\title{
Phosphonate inhibition as a function of phosphate concentration in isolates of Phytophthora palmivora
}

\author{
Julia M. Griffith, ${ }^{1}$ Michael D. CoffeY ${ }^{3}$ and Bruce R. Grant ${ }^{2 *}$ \\ ${ }^{1}$ Department of Microbiology and ${ }^{2}$ Russell Grimwade School of Biochemistry, University of Melbourne, Parkville, \\ Victoria 3052 Australia \\ ${ }^{3}$ Department of Plant Pathology, University of California, Riverside, California, USA
}

(Received 29 January 1993; revised 16 April 1993; accepted 20 April 1993)

\begin{abstract}
Three isolates of Phytophthora palmivora showing differing sensitivities to phosphonate were grown in the presence of a uniform concentration of the anion $(1 \mathrm{mM})$, together with concentrations of phosphate which varied from zero to $3 \mathrm{mM}$. The phosphonate-sensitive isolate was inhibited by phosphonate at all levels of phosphate, but the resistant isolates were inhibited by phosphonate only when phosphate was limiting to growth and were able to exclude phosphonate more effectively than the sensitive isolate at higher concentrations of phosphate. The percentage inhibition in each strain was proportional to the internal concentration of phosphonate, but the slope of the plot of inhibition against internal phosphonate varied between strains. Differences in the capacity to discriminate between phosphate and phosphonate therefore provide part of, but not the whole explanation for differences in sensitivity between isolates. There was a significant increase in the internal concentration of orthophosphate in the mycelia which were inhibited by phosphonate.
\end{abstract}

\section{Introduction}

The mechanism by which phosphonates (syn. phosphites) act to control plant diseases remains unknown, though it appears that both direct and indirect effects play a role in activity (Guest \& Grant, 1991). Recent studies (Barchietto et al., 1992; Dunstan et al., 1990; Griffith et al., 1990; Niere et al., 1990; J. O. Niere \& B. R. Grant, unpublished) have identified alterations to the metabolism of Phytophthora spp. grown in the presence of phosphonate, with specific effects on the metabolism of phosphorus-containing compounds. It has also been clearly established (Bompeix \& Saindrenan, 1984; Fenn \& Coffey, 1984) that the toxicity of the phosphonate anion against Phytophthora spp. in culture is determined in part by the concentration of phosphate present in the medium $\left(\mathrm{Pi}_{\mathrm{e}}\right)$, resulting from competition between phosphate and phosphonate anions for the phosphate transport system. Two phosphate transporters have been identified, a low-affinity system present constitutively and a high-affinity system induced only when the $\mathrm{Pi}_{e}$ in the medium becomes limiting (Barchietto et al., 1989;

\footnotetext{
*Author for correspondence. Tel. 3344 5938; fax 3347 7730; e-mail
} b.grant@biochemistry.unimelb.edu.au.

Abbreviations: $\mathrm{Pi}_{\mathrm{c}}$, phosphate in the medium; $\mathrm{Pi}_{\mathrm{i}}$, phosphate extracted from mycelium.
Griffith et al., 1989a). The toxicity of any given concentration of phosphonate is thus dependent on the $\mathrm{Pi}_{\mathrm{e}}$ concentration.

Phosphonates do not exhibit broad spectrum activity and have proved most effective against members of the order Peronosporales, although evidence is emerging that phosphonate anion toxicity may not be entirely restricted to members of the Oomycetes (Davis et al., 1993; Heaton \& Dullahide, 1990). However, even within the genus Phytophthora cultured at the same $\mathrm{Pi}_{\mathrm{e}}$ concentration, different species and isolates vary considerably in their sensitivity to phosphonate. The same variation in efficacy is observed in control of diseases in the field (Cohen \& Coffey, 1986; Coffey \& Ouimette, 1989; Griffith et al., 1992).

Given that in Phytophthora spp. phosphate and phosphonate share common transporters, differences in sensitivity to phosphonate within the genus may result from variation in the capacity of these transporters to discriminate between $\mathrm{Pi}_{\mathrm{e}}$ and phosphonate, with resistant isolates restricting access of phosphonate to a target site or sites within the cell. We have investigated this possibility using three isolates of Phytophthora palmivora exhibiting very different sensitivities to phosphonate in culture. Our results suggest that while there are clear differences between sensitive and resistant isolates in their capacity to discriminate between the two anions, 
this does not provide a complete explanation of selectivity, and there appear to be differences in the sensitivity of internal target sites to the phosphonate anion.

\section{Methods}

Chemicals. Phosphorous acid (hydrogen phosphonate) was obtained from Albright \& Wilson as solid flakes. Potassium phosphonate solutions were freshly prepared for each experiment and adjusted to $\mathrm{pH} 6.2$ with $\mathrm{KOH}$. Other chemicals were obtained from Sigma, BDH or Merck. Carrier-free ${ }^{32} \mathrm{PO}_{4}^{3-}$ was obtained from the Australian Atomic Energy Commission.

Culture and growth of organisms. Three isolates of Phytophthora palmivora were used. All were obtained from the Phytophthora culture collection at the University of California, Riverside. The history of Phytophthora palmixora isolate P113 (ATCC 26286) was described by Tokunaga \& Bartnicki-Garcia (1971). This strain has been used in our laboratory for several years (Grant et al., 1984) and exhibits a high $\mathrm{ED}_{5_{0}}$ for phosphonate in culture (Griffith et al., 1989 b). P. palmivora P376, is considerably more sensitive to phosphonate (Dolan \& Coffey, 1988). P. palmivora $P 7228$ was derived from $P 376$ by mutagenesis of zoospores (Dolan \& Coffey, 1988). All three isolates were maintained on V8 agar plates from which $\mathrm{CaCO}_{3}$ had been omitted (Irving et al., 1984).

Organisms were cultured on a defined mineral salts medium (Ribeiro et al., 1975) as modified by Fenn \& Coffey (1984), except that the $\mathrm{Pi}_{\mathrm{e}}$ concentration was varied according to experimental demands. Medium without phosphate is referred to as ' $0 \mathrm{PR}$ '. Mycelia were grown in $50 \mathrm{ml}$ medium in $250 \mathrm{ml}$ Erlenmyer flasks which had been rinsed with $5 \%$ (v/v) nitric acid and then with distilled water before use. Potassium phosphate was added to the required concentration before autoclaving. Phosphonate, adjusted to $\mathrm{pH} 6 \cdot 2$ with $\mathrm{KOH}$, was autoclaved separately and added to the sterilized media. Each flask was inoculated with mycelium grown on LPR agar as described previously (Griffith et al., $1989 b$ ).

In some experiments the fungus was grown on an enriched medium (SYPGR medium) based on that of Hendrix \& Apple (1964) and Hendrix (1965). It contained $\left(\mathbf{1}^{-1}\right)$ : neutralized soy peptone (Oxoid), $6 \mathrm{~g}$; yeast extract (Oxoid), $0.5 \mathrm{~g} ; \mathrm{KH}_{2} \mathrm{PO}_{4}, \mathrm{lg}$; glucose, $20 \mathrm{~g}$; and rye seed extract (Caten \& Jinks, 1968), $100 \mathrm{ml}$.

Flasks were incubated at $26^{\circ} \mathrm{C}$ in the dark, normally without shaking, for up to $14 \mathrm{~d}$. Mycelium was harvested by vacuum filtration onto preweighed filters (Whatman GF/C), washed with distilled water and the dry weights determined after freeze-drying. Where shake cultures were grown, an orbital shaker operating at 100 oscillations $\min ^{-1}$ was used.

Uptake studies. Phosphate uptake was measured using a procedure similar to that described by Barchietto et al. (1989) with suspensions of homogenized mycelium. These were prepared as follows. SYPGR medium ( $50 \mathrm{ml}$ in a $250 \mathrm{ml}$ flask) was inoculated with an agar plug of the relevant fungal strain and incubated at $26^{\circ} \mathrm{C}$ without shaking. After several days growth, the mycelium was macerated with a sterile Ultra-Turrax homogenizer (Janke \& Kunkel) for about $30 \mathrm{~s}$. A sample $(2-5 \mathrm{ml})$ of the homogenized material was then inoculated into $50 \mathrm{ml}$ SYPRG medium and shaken for 1-2 d, after which the culture was homogenized again (Rawn \& Van Etten, 1974; Zweck et al., 1978). This was repeated until a uniform suspension was obtained. Each culture was checked for contamination both visually and by inoculating a sample in $2 \%(\mathrm{w} / \mathrm{v})$ Bacto-Peptone (Difco) and incubating at $26^{\circ} \mathrm{C}$.

Mycelium was harvested by vacuum filtration onto Whatman no. 1 paper, washed with several volumes of one-third-strength OPR and resuspended in this medium. Mycelial suspensions were dispensed, in $50 \mathrm{ml}$ aliquots, into $250 \mathrm{ml}$ flasks containing various concentrations of ${ }^{32} \mathrm{P}$-phosphate ranging from $5-40 \mu \mathrm{M}$ [specific activities ranging from 1-2 $\left.\mathrm{mCi}(37-74 \mathrm{MBq}) \mathrm{mmol}^{-1}\right]$ and shaken as described above. At various times over a period of $90 \mathrm{~min}, 5 \mathrm{ml}$ aliquots were withdrawn and filtered onto preweighed $\mathrm{GF} / \mathrm{C}$ filters. Each sample was washed with $3 \times 10 \mathrm{ml}$ aliquots of $5 \mathrm{~mm}$-potassium phosphate buffer $(\mathrm{pH} 7)$, freeze-dried and weighed. The radioactivity of the samples was measured in an LKB model 1217 scintillation counter after the addition of scintillation fluid (Optiphase HiSafe II, LKB). As the uptake of Pi by the mycelium showed a lag period of some $30 \mathrm{~min}$ following transfer to the defined medium, uptake rates were determined from the point at which the rates became linear.

Preparation of mycelial extracts. Four millilitres of $0.33 \mathrm{~m}$ ice-cold formic acid was added to the frecze-dried mycelia. After $30 \mathrm{~min}$ the mycelium was removed by vacuum filtration and the formic-acidextract freeze-dried to remove formic acid. The samples were adjusted to a known volume and the phosphate and phosphonate content determined. Previous studies had shown that this method completely extracted phosphate and phosphonate, although it was less effective than perchloric acid in extraction of short chain polyphosphates (Niere et al., 1990).

Determination of phosphate and phosphonate content of extracts. Reconstituted formic-acid-extracts were separated on a $4.6 \times 75 \mathrm{~cm}$ anion-exchange column (IC-PAK A HR column, Waters). The eluant consisted of $0.32 \mathrm{~g}$ sodium gluconate, $0.36 \mathrm{~g}$ boric acid, $0.5 \mathrm{~g}$ sodium tetraborate decahydrate, $5 \mathrm{ml}$ glycerine, $20 \mathrm{ml} \mathrm{l-butanol}$ and $120 \mathrm{ml}$ acetonitrile made to 1 litre with Milli-Q water according to the manufacturer's instructions. Anions in the eluant were analysed using a conductivity detector (LDC/Milton Roy). The chromatographic data were acquired and analysed using a chromatography program manufactured by DAPA Scientific Software, Kalamunda, Western Australia. Phosphate and phosphonate were identified and quantified by comparison with known standards.

Replication and reproducibility of experiments. All growth experiments were carried out at least three times. Measurements of kinetic parameters (see Table 4) were done twice. Results presented in Figures and Tables are representative, although actual growth levels varied from one experiment to another, particularly with the mutant P7228. Where statistically significant differences are reported between pairs of data points, Student's $t$-test was used.

\section{Results}

\section{Effect of varying phosphate concentrations on the toxicity of phosphonate}

The inhibition of growth by phosphonate (1 mM) was examined over a wide range of $\mathrm{Pi}_{\text {. }}$ concentrations. These extended from growth limiting $(10 \mu \mathrm{M}-100 \mu \mathrm{M})$ to excess ( $1 \mathrm{~mm}$ and above) levels. The results of typical experiments are shown in Fig. 1. The resistant isolate, P113, always showed some growth in the presence of phosphonate, even at the lowest $\mathrm{Pi}_{\mathrm{e}}$ concentration tested, $10 \mu \mathrm{M}$, where the ratio of phosphonate to phosphate was 100 and growth was severely phosphorus-limited (Fig. 1a). In the particular experiment shown, there was no inhibition of growth by phosphonate when $\mathrm{Pi}_{\mathrm{e}}$ concentration exceeded $1 \mathrm{~mm}$. However, in some experiments, slight inhibition was detected under these con- 


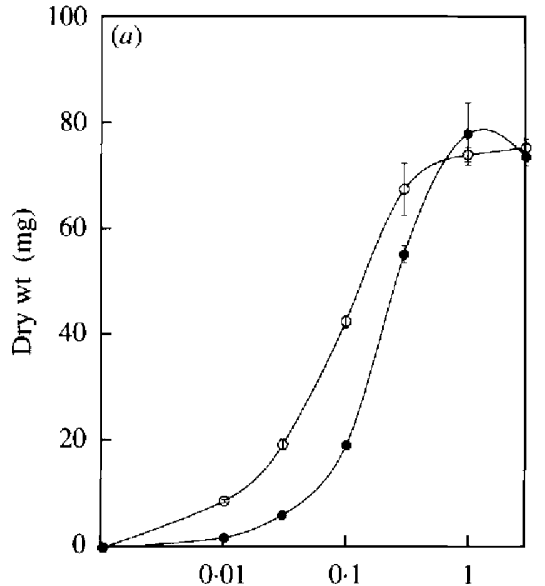

Phosphate concn (mM)

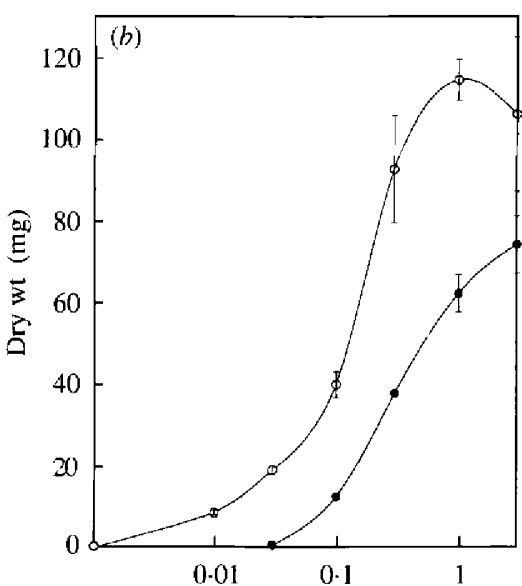

Phosphate concn (mM)

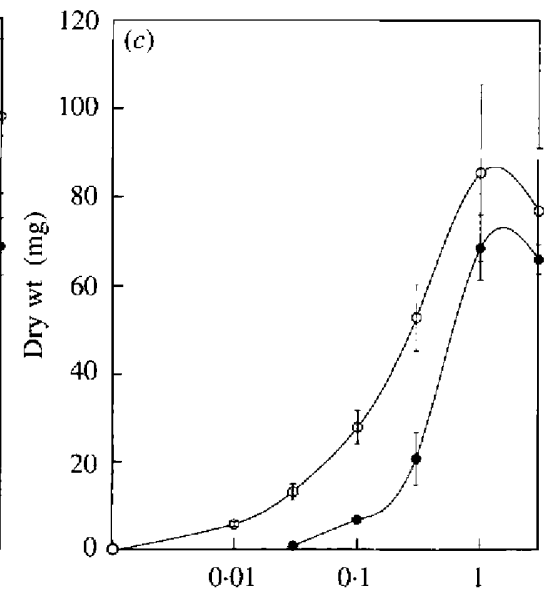

Phosphate concn (mM)

Fig. 1. Effect of increasing phosphate concentration on inhibition of growth of three isolates of $P$. palmivora. $\bigcirc$, Control;, treated with 1 mm-phosphonate. (a) Isolate P113, resistant to phosphonate; (b) isolate P376, sensitive to phosphonate; (c) P7228, a resistant mutant derived from P376. All cultures were grown at $26^{\circ} \mathrm{C}$ in the dark on minimal mineral salts medium with varying levels of phosphate. P113 was grown for $9 \mathrm{~d}, \mathrm{P} 376$ and P7228 for $14 \mathrm{~d}$. Data points are means of four replicates with error bars showing the standard deviation where larger than the symbol.
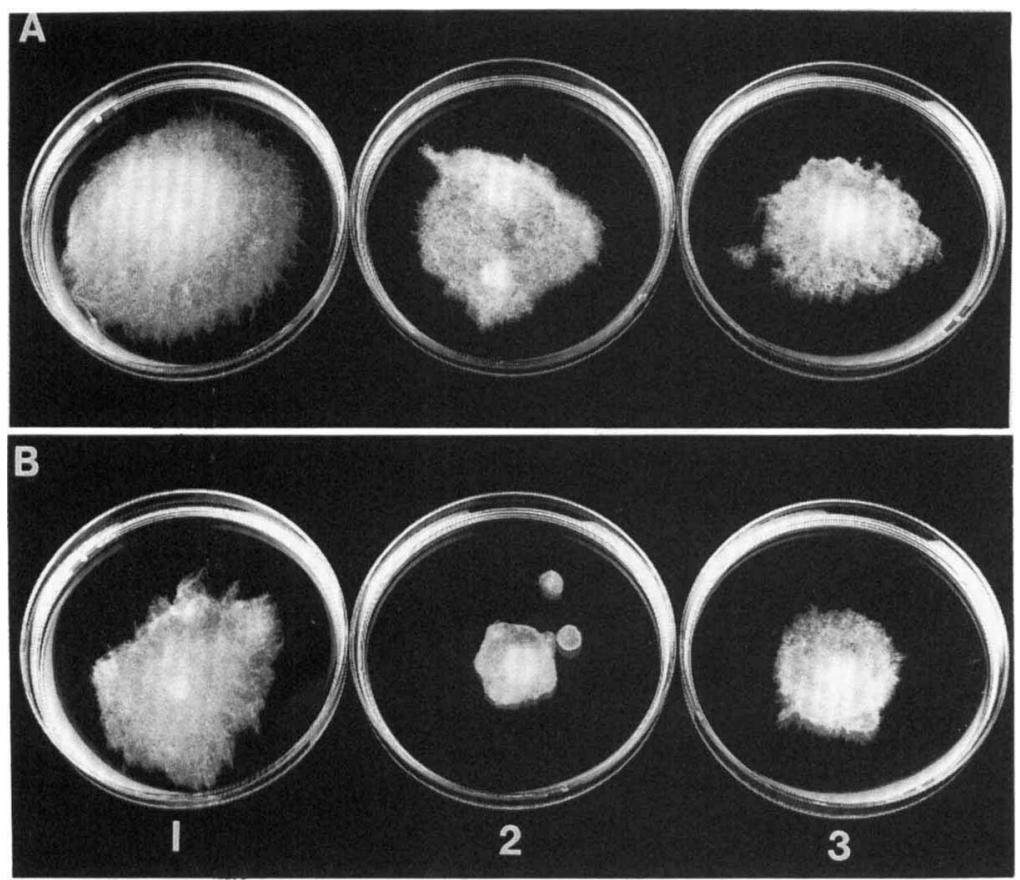

Fig. 2. Effect of phosphonate on morphology of $P$. palmivora. (A) Typical appearance of the isolates grown in LPR; (B) the appearance in the same medium containing $1 \mathrm{~mm}$-phosphonate. Sample 1 , P113; sample 2, P376; sample 3, P7228. Only P376 shows the marked difference in culture morphology in the presence of phosphonate. The sample of P113 was grown for $9 \mathrm{~d}, \mathrm{P} 376$ and P7228 for $14 \mathrm{~d}$.

ditions. Similar results have been reported from previous studies (Dunstan et al., 1990; Griffith et al., 1989 b). In contrast, the growth of the phosphonate-sensitive isolate P376 was reduced at all $\mathrm{Pi}_{\mathrm{c}}$ concentrations tested (Fig. $1 b$ ). This isolate showed almost no growth in the presence of phosphonate at the lower $\mathrm{Pi}_{\mathrm{e}}$ concentrations $(10-30 \mu \mathrm{M})$ and measurable growth was observed only when $\mathrm{Pi}_{c}$ concentration exceeded $0.1 \mathrm{~mm}$.

The mycelium of P376 grown in the presence of phosphonate was clearly distinguishable in appearance from untreated mycelium (Fig. 2). In the absence of phosphonate, the mycelium grew as fluffy islands, eventually spreading over the surface of the medium. In the presence of the anion it grew in tight clumps which sank to the bottom of the flask. These differences were not evident in either the P113 or the P7228 isolates (Fig. 2).

Differences were also visible at the microscopic level. The phosphonate-treated hyphae appeared more branched, twisted and distorted. It was not possible to 


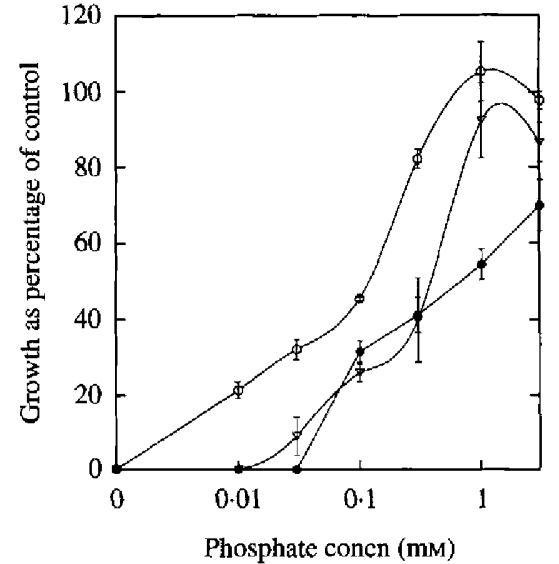

Fig. 3. Inhibition of growth by $1 \mathrm{~mm}$-phosphonate at various levels of phosphate. Data from Fig. 1 were replotted to show relative inhibition as a function of phosphate level for each of the three strains: $\mathrm{O}, \mathrm{P} 113$; - $\mathrm{P} 376 ; \nabla, \mathrm{P} 7228$.

\section{Table 1. Extractable phosphate and phosphonate} present in mycelium of $P$. palmivora $P 113$

The mycelium was harvested after growth for $9 \mathrm{~d}$ in modified Ribeiro's medium containing variable levels of phosphate and 1 mM-potassium phosphonate, extracted with formic acid and analysed for its content of $\mathrm{Pi}_{\mathrm{i}}$ and phosphonate as described in Methods. Phosphonate was not detectable in the control samples and is shown for phosphonate-treated samples only in Tables 1-3.

\begin{tabular}{lccc}
\hline \hline $\begin{array}{l}\mathrm{P}_{\mathrm{i}} \text { in } \\
\text { growth } \\
\text { medium }\end{array}$ & $\begin{array}{c}\mathrm{Pi}_{\mathrm{i}}\left[\mathrm{nmol}(\mathrm{mg} \mathrm{dry} \mathrm{wt})^{-1}\right] \\
\text { mycelium }\end{array}$ & $\begin{array}{c}\text { Treated } \\
\text { mycelium }\end{array}$ & $\begin{array}{c}\text { Phosphonate } \\
\text { [nmol (mg dry } \\
\mathrm{wt}^{-1} \text { ] }\end{array}$ \\
\hline $10 \mu \mathrm{M}$ & $13 \cdot 1 \pm 1 \cdot 7$ & $33 \cdot 2 \pm 10 \cdot 4$ & $102 \cdot 8 \pm 13 \cdot 1$ \\
$30 \mu \mathrm{M}$ & $17 \cdot 3 \pm 0 \cdot 6$ & $21 \cdot 9 \pm 10 \cdot 9$ & $55 \cdot 0 \pm 11 \cdot 0$ \\
$100 \mu \mathrm{M}$ & $24 \cdot 9 \pm 3 \cdot 6$ & $24 \cdot 2 \pm 4 \cdot 0$ & $57 \cdot 4 \pm 2 \cdot 8$ \\
$300 \mu \mathrm{M}$ & $27 \cdot 2 \pm 2 \cdot 4$ & $16 \cdot 7 \pm 1 \cdot 3$ & $42 \cdot 2 \pm 9 \cdot 9$ \\
$1 \mathrm{mM}$ & $25 \cdot 3 \pm 4 \cdot 6$ & $24 \cdot 2 \pm 10 \cdot 1$ & $7 \cdot 6 \pm 4 \cdot 2$ \\
$3 \mathrm{mM}$ & $20 \cdot 8 \pm 4 \cdot 5$ & $19 \cdot 9 \pm 3 \cdot 5$ & $5 \cdot 1 \pm 1 \cdot 5$ \\
\hline \hline
\end{tabular}

quantify the degree of twisting, and an attempt to quantify branching by measuring distances between the hyphal tip and the first branch showed wide variation and the effect of phosphonate on this parameter was not significant. These effects of phosphonate were not observed in either the P113 or P7228 isolates.

Isolate P7228, the phosphonate-resistant mutant selected from P376, resembled its parent rather than the naturally resistant isolate $\mathrm{P} 113$ in its sensitivity to phosphonate at low levels of phosphate (Fig. 1c). However, at higher levels of phosphate $(0.3 \mathrm{~mm}$ and above) phosphonate was less inhibitory to growth, and resistance to the effects of this anion was clearly demonstrated. These effects can be seen in Fig. 3, in which the inhibition by phosphonate at each level of
Table 2. Extractable phosphate and phosphonate present in mycelium of $P$. palmivora $P 376$

The mycelium was harvested after growth for $14 \mathrm{~d}$ in modified Ribeiro's medium containing variable levels of phosphate and 1 mM-potassium phosphonate, extracted with formic acid and analysed for its content of $\mathrm{Pi}_{\mathrm{i}}$ and phosphonate as described in Methods.

\begin{tabular}{|c|c|c|c|}
\hline \multirow{2}{*}{$\begin{array}{l}\text { Pi in } \\
\text { growth } \\
\text { medium }\end{array}$} & \multicolumn{2}{|c|}{$\left.\mathrm{Pi}_{\mathrm{i}}[\text { nmol (mg dry wt) })^{-1}\right]$} & \multirow{2}{*}{$\begin{array}{l}\text { Phosphonate } \\
{[\mathrm{nmol}(\mathrm{mg} \text { dry }} \\
\left.\text { wt })^{-1]}\right]\end{array}$} \\
\hline & $\begin{array}{c}\text { Control } \\
\text { mycelium }\end{array}$ & $\begin{array}{c}\text { Treated } \\
\text { mycelium }\end{array}$ & \\
\hline $10 \mu \mathrm{M}$ & $10 \cdot 7 \pm 3 \cdot 4$ & $-^{*}$ & $-^{*}$ \\
\hline $30 \mu \mathrm{M}$ & $11 \cdot 1 \pm 2 \cdot 0$ & $95.4 \pm 53.8$ & $373 \cdot 4 \pm 189$ \\
\hline $100 \mu \mathrm{M}$ & $21.0 \pm 1.5$ & $86 \cdot 1 \pm 3 \cdot 9$ & $66 \cdot 3 \pm 1 \cdot 6$ \\
\hline $300 \mu \mathrm{M}$ & $29 \cdot 9 \pm 6.8$ & $75 \cdot 3 \pm 2 \cdot 7$ & $28 \cdot 4 \pm 2 \cdot 6$ \\
\hline $1 \mathrm{~mm}$ & $55 \cdot 1 \pm 2 \cdot 3$ & $68 \cdot 1 \pm 4 \cdot 3$ & $8 \cdot 9 \pm 2 \cdot 6$ \\
\hline $3 \mathrm{~mm}$ & $51.0 \pm 3.6$ & $60 \cdot 1 \pm 4 \cdot 1$ & $8 \cdot 8 \pm 0-9$ \\
\hline
\end{tabular}

* No increase in dry weight could be detected in mycelium grown in $10 \mu \mathrm{M}-\mathrm{Pi}$ in the presence of I mM-phosphonate, although a small amount of growth was visible to the eye. The amount of $\mathbf{P}_{\mathrm{i}}$ extracted from these samples was $19.6 \pm 3.5 \mathrm{nmol}$, and the amount of phosphonate $155 \cdot 2 \pm 18 \cdot 7 \mathrm{nmol}$.

Table 3. Extractable phosphate and phosphonate present in mycelium of $P$. palmivora $P 7228$

The mycelium was harvested after growth for $14 \mathrm{~d}$ in modified Ribeiro's medium containing variable concentrations of phosphate and $1 \mathrm{~mm}$-potassium phosphonate, extracted with formic acid and analysed for its content of $\mathrm{Pi}_{\mathrm{i}}$ and phosphonate as described in Methods.

\begin{tabular}{|c|c|c|c|}
\hline \multirow{2}{*}{$\begin{array}{l}\mathrm{Pi} \text { in } \\
\text { growth } \\
\text { medium }\end{array}$} & \multicolumn{2}{|c|}{$\mathrm{Pi}_{\mathrm{i}}\left[\mathrm{nmol}(\mathrm{mg} \text { dry wt })^{-1}\right]$} & \multirow{2}{*}{$\begin{array}{c}\text { Phosphonate } \\
\text { [nmol (mg dry } \\
\left.\text { wt })^{-1}\right]\end{array}$} \\
\hline & $\begin{array}{l}\text { Control } \\
\text { mycelium }\end{array}$ & $\begin{array}{l}\text { Treated } \\
\text { mycelium }\end{array}$ & \\
\hline $10 \mu \mathrm{M}$ & $9 \cdot 7 \pm 1 \cdot 1$ & $-*$ & _** \\
\hline $30 \mu \mathrm{M}$ & $14 \cdot 6 \pm 6 \cdot 3$ & $207 \cdot 5 \pm 112-9$ & $46 \cdot 9 \pm 30 \cdot 2$ \\
\hline $100 \mu \mathrm{M}$ & $31.2 \pm 11.5$ & $525 \cdot 9 \pm 76.4$ & $166 \cdot 5 \pm 53 \cdot 2$ \\
\hline $300 \mu \mathrm{M}$ & $60.8 \pm 8.2$ & $164.5 \pm 31.7$ & $33 \cdot 9 \pm 23 \cdot 2$ \\
\hline $1 \mathrm{~mm}$ & $95 \cdot 8 \pm 18.9$ & $187 \cdot 3 \pm 23 \cdot 0$ & $8 \cdot 5 \pm 3 \cdot 5$ \\
\hline $3 \mathrm{~mm}$ & $107 \cdot 3 \pm 24.6$ & $175.7 \pm 18.1$ & $4 \cdot 9 \pm 0.6$ \\
\hline
\end{tabular}

* No increase in dry weight could be detected in mycelium grown in $10 \mu \mathrm{M}-\mathrm{P}_{\mathrm{i}}$ in the presence of phosphonate, although a small amount of growth was visible to the eye.

phosphate is expressed as a percentage of the growth in the control at that level.

\section{Concentrations of phosphate and phosphonate in mycelia}

Tables 1-3 compare the levels of formic acid-extractable phosphate $\left(\mathrm{Pi}_{\mathrm{i}}\right)$ and phosphonate in mycelia from the experiments depicted in Fig. 1. These data show clear differences between the three isolates. At lower $\mathrm{Pi}_{\mathrm{e}}$ concentrations $(10-100 \mu \mathrm{M})$, in the absence of phospho- 
nate, the amount of $\mathrm{Pi}_{\mathrm{i}}$ extracted was comparable in the three strains and increased with increasing $\mathrm{Pi}_{\mathrm{e}}$ concentration. However, when $\mathrm{Pi}_{\mathrm{e}}$ did not limit growth, at $1 \mathrm{~mm}$ and $3 \mathrm{mM}$, the P376 and P7228 strains accumulated more $\mathrm{Pi}_{\mathrm{i}}$ (mg dry wt) ${ }^{-1}$ than $\mathrm{P} 113$. In $\mathrm{P} 7228$ this was also evident at $300 \mu \mathrm{M}$.

When growth was phosphate-limited, the level of $\mathrm{Pi}_{\mathrm{i}}$ ( $\mathrm{g}$ dry $w t)^{-1}$ in the presence of phosphonate was always higher than in the controls (Tables 1-3). This additional $\mathrm{Pi}_{\mathrm{i}}$ content was still evident in phosphonate-treated P376 and $\mathrm{P} 7228$ when $\mathrm{Pi}_{e}$ concentrations exceeded $300 \mu \mathrm{M}$, but was not observed in the resistant strain (P113) when phosphate did not inhibit growth.

The amount of phosphonate accumulated within the mycelium by all three isolates decreased as $\mathrm{Pi}_{\mathrm{e}}$ concentration increased (Tables 1-3). This would be predicted from what is known of the competition between the two anions for a common transport system (Barchietto et al., 1989; Griffith et al., 1989a). However, the data show that at higher $\mathrm{Pi}_{\mathrm{e}}$ concentrations, the two resistant strains were more effective in excluding phosphonate, suggesting that there are differences in the capacity of the transporter system to discriminate between the two anions.

When percentage inhibition at each external phosphate level, was plotted as a function of internal phosphonate concentration (Fig. 4) it was found that the degree of inhibition for each isolate increased as the internal concentration of phosphonate increased. However, the slope of the regression curve for the data from each isolate was different. At $50 \%$ inhibition, the internal concentrations of phosphonate were similar : $27 \mu \mathrm{mol} \mathrm{g}^{-1}$ for $\mathrm{P} 113,13.5 \mu \mathrm{mol} \mathrm{g} \mathrm{g}^{-1}$ for $\mathrm{P} 376$ and $29 \mu \mathrm{mol} \mathrm{g}^{-1}$ for P7228. However at $90 \%$ inhibition, less phosphonate was present in the resistant isolate P113, than in the sensitive isolate $\mathrm{P} 376$, while at $25 \%$ inhibition there was less phosphonate present in the sensitive than in the resistant isolate.

\section{Phosphate uptake measurements}

Previous studies (Griffith et al, 1989a), using $P$. palmivora $\mathrm{P} 113$, indicated that phosphonate was taken into the cell via two systems for the transport of $\mathrm{Pi}_{\mathrm{e}}$. One was constitutive, with a low affinity for phosphate $\left(K_{m}\right.$ approx. $30 \mu \mathrm{M})$, the other, induced under conditions of phosphorus deprivation, had a higher affinity $\left(K_{\mathrm{m}}\right.$ $1-2 \mu \mathrm{M})$. The higher resistance of P113 to phosphonate is partly due to the lower level of phosphonate accumulated at higher phosphate concentrations. This could result from the presence of a transport system with a reduced affinity for phosphate and hence phosphonate (Rosenberg \& La Nauze, 1968). To test this possibility, the kinetic parameters for $\mathrm{Pi}_{\mathrm{e}}$ uptake were compared in the

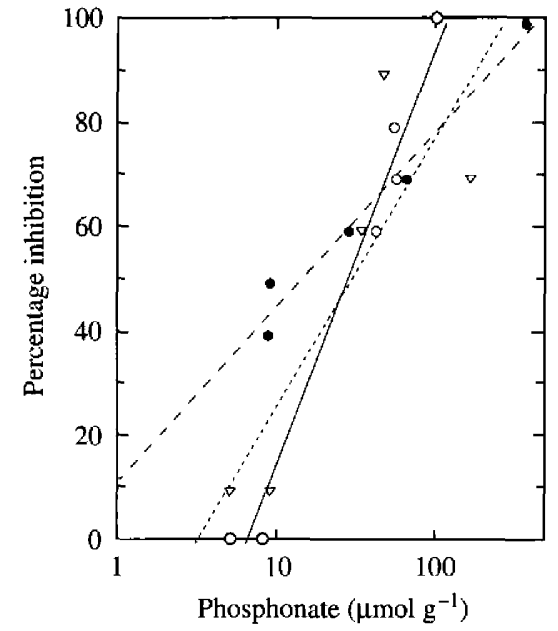

Fig. 4. Inhibition of growth of $P$. palmivora as a function of internal phosphonate concentration. Mycelia from the growth experiment depicted in Tables 1-3 were extracted and the phosphonate separated and quantified as described in the text. Curves were computer-fitted to the data. Regression coefficients for the inhibition of P113 and P376 were 0.98 , and that for P7228 was 0.85 . Symbols as for Fig. 3.

Table 4. Kinetic parameters of the low-affinity transport system for the uptake of phosphate in Phytophthora palmivora mycelium

The methods used are described in the text. The results are from at least two experiments.

\begin{tabular}{ll}
\hline \hline & $K_{\mathrm{m}}(\mu \mathrm{M})$ \\
\hline P. palmivora P113 & (1) $24 \pm 1$ \\
& $(2) 25 \pm 5$ \\
P. palmivora P376 & (1) $30 \pm 2$ \\
& (2) $23 \pm 1$ \\
P. palmivora P7228 & (1) $22 \pm 4$ \\
& (2) $22 \pm 5$ \\
& (3) $30 \pm 5$ \\
\hline \hline
\end{tabular}

three strains. The maximum rate of uptake of $\mathrm{Pi}_{\mathrm{e}}$ varied from one experiment to another [ranging from 30 to

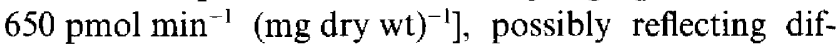
ferences in the number of phosphate-binding sites present on the mycelium at the time of assay. However, there was no consistent pattern of difference in the kinetics of phosphate uptake between the strains, each being capable of high rates of uptake of $\mathrm{Pi}_{\mathrm{e}}$. The values determined for the $K_{\mathrm{m}}$ of the low-affinity phosphate transporter were similar in all three strains (Table 4) and were of the same order of magnitude as determined previously for P113 using preparations of germinated zoospores, rather than homogenized mycelial preparations (Griffith et al., $1989 a$ ). Because of the limitations in accuracy when mycelial homogenates were used instead of germinating zoospores, no attempt was made to determine $K_{\mathrm{m}}$ values 
Table 5. Comparison of the rate of uptake of Pi by strains of Phytophthora palmivora before and after $4 \mathrm{~h}$ of phosphorus deprivation

\begin{tabular}{lcc}
\hline \hline & $\begin{array}{c}\text { Rate of Pi uptake } \\
{\left[\mathrm{nmol} \mathrm{min}{ }^{-1}(\mathrm{mg} \text { dry wt })^{-1}\right]}\end{array}$ \\
\cline { 2 - 3 } Organism & $\begin{array}{c}\text { Before Pi } \\
\text { starvation }\end{array}$ & $\begin{array}{c}\text { After Pi } \\
\text { starvation }\end{array}$ \\
\hline P. palmizora P113 & $0 \cdot 4$ & $2 \cdot 7$ \\
P. palmivora P376 & $0 \cdot 1$ & $0 \cdot 6$ \\
P. palmivora P7228 & $0 \cdot 4$ & $1 \cdot 8$ \\
\hline
\end{tabular}

for the high-affinity phosphate transporter. However, it was shown that the rate of uptake of $\mathrm{Pi}_{\mathrm{e}}$ increased fourto sixfold in each of the strains following phosphorus deprivation (Table 5), indicating that phosphate starvation resulted in increased rates of phosphate assimilation. The much lower rate of $\mathrm{Pi}_{\mathrm{e}}$ uptake in the phosphate-starved P376 may be the result of a reduced capacity to produce a high affinity transporter under the conditions of these experiments.

\section{Discussion}

Our results demonstrate quantitatively the marked difference in sensitivity to phosphonate between $P$. palmivora isolates P113 and P376, originally reported by Dolan \& Coffey (1988), and show that this difference is expressed over a wide range of phosphate concentrations. The resistant mutant derived from P376, P7228, resembled its parent at low phosphate concentrations, but at higher levels showed resistance to phosphonate comparable to P113. The response of P113 is consistent with earlier data obtained with this isolate (Griffith et al., 1989 b; Smillie et al., 1989) in which it was shown that the $\mathrm{ED}_{50}$ was approximately $30 \mathrm{~mm}$-phosphonate at $7 \mathrm{mM}$ $\mathrm{Pi}_{\mathrm{e}}$, but $1 \mathrm{~mm}$ at $0.1 \mathrm{~mm}-\mathrm{Pi}_{\mathrm{e}}$. The data show that at physiological concentrations of phosphate, $1 \mathrm{~mm}$ phosphonate is essentially without effect on this isolate, in contrast to the sensitive isolate P376, which is inhibited by $1 \mathrm{~mm}$-phosphonate at even the highest phosphate levels supplied.

The data also show that the sensitive isolate P376 accumulated more phosphonate than its resistant counterparts under all conditions, supporting the hypothesis that one difference between resistant and sensitive organisms lies in their capacity to exclude phosphonate, particularly at high phosphate concentrations. This interpretation is supported by parallel work which has been carried out on Fusarium oxysporum f.sp. cubense and $F$. avenaceum, two ascomycetes which also show sensitivity to phosphonate (Davis et al., 1993). F. oxysporum f.sp. cubense, which is the more resistant species, was able to exclude phosphonate over a wide range of external phosphate concentrations, while in $F$. avenaceum, a species relatively sensitive to phosphonate, the ratio of phosphate to phosphonate inside the mycelium paralleled the ratio of the two ions in the growth medium (A. J. Davis \& B. R. Grant, unpublished).

At $\mathrm{Pi}_{\mathrm{e}}$ concentrations below $0.1 \mathrm{~mm}$, the situation in $P$. palmivora is complex because the ratio of $\mathrm{Pi}$ to phosphonate is lower and hence the competition for the transporter is altered in favour of phosphonate, and because the high affinity phosphate transport system is induced under these conditions. In isolate P113, phosphonate enters the fungus in large amounts only after $\mathrm{Pi}_{\mathrm{e}}$ has been depleted (Griffith et al., 1989 b). At levels of 1 and $3 \mathrm{mM}^{-P i_{e}}$, where only the low affinity phosphate transport system would be operating throughout growth (as phosphate is not the limiting nutrient) P113 accumulated only one third of the amount of phosphonate (g dry wt) $)^{-1}$ accumulated by P376. Strain P7228 accumulated intermediate amounts.

This result can be interpreted as evidence that the constitutive phosphate transporter in resistant strains is more effective in excluding phosphonate than that in the sensitive strain, although other data suggest that the situation is more complex. Barchietto et al. (1989) found that neither the $K_{\mathrm{m}}$ nor the $V_{\max }$ for phosphonate transport correlated with phosphonate resistance in Phytophthora cryptogea and Phytophthora citrophthora, the more resistant strain having the lower $K_{\mathrm{m}}$ and higher $V_{\text {max }}$ for phosphonate. Our studies also show no correlation between phosphonate sensitivity and affinity of the constitutive transporter for phosphate, with the $K_{\mathrm{m}}$ for phosphate in the low-affinity transporter similar in each strain. More detailed kinetic studies, including studies on phosphonate uptake directly, possibly using isolated transporter protein in a liposomal system, will be required to determine the extent to which the differences in phosphonate accumulation result from differences in the properties of the phosphate transport systems.

It has been suggested elsewhere (Barchietto et al., 1988) that the resistance to phosphonate in Nectria haematococca resulted from a capacity to oxidize phosphonate to phosphate. However, we have found no evidence of phosphonate oxidation in $P$. palmivora in this or in previous studies (Griffith et al., 1990; Niere et al., 1990).

Our data also show that, regardless of the mechanism which determines the final level of phosphonate present in the organism, there are also differences between isolates in their sensitivity to a given internal concentration of phosphonate. Each isolate showed a correlation between the log of the internal phosphonate 
concentration and the percentage inhibition of growth of that isolate. However, the slopes of the regression lines were significantly different for each of the three isolates $(79,33$ and 51$)$, indicating differences in sensitivity to the anion at one or more internal sites. This was in contrast to findings for the two species of Fusarium referred to above (A. J. Davis \& B. R. Grant, unpublished). In these species inhibition was also directly correlated with internal phosphonate concentration, but there was no difference in the slope of the regression curve between the species. Therefore we conclude that in these species of Fusarium there are no differences in sensitivity at the site at which phosphonate acts internally.

As differences in capacity to exclude phosphonate do not provide a full explanation of differential resistance between the isolates of $P$. palmivora, there must also be differential sensitivity to the anion at one or more internal sites. This conclusion is supported by measurements of extractable phosphonate levels made on a number of Phytophthora spp. using ${ }^{31} \mathrm{P}$ NMR (J. O. Niere \& B. R. Grant, unpublished). These showed that very different levels of internal phosphonate resulted in the same level of growth inhibition in different species. The extreme case was that of P. melonis, in which $50 \%$ inhibition was observed at an internal phosphonate concentration of only $5 \mu \mathrm{mol} \mathrm{g}{ }^{-1}$, contrasting with $14 \mu \mathrm{mol} \mathrm{g}^{-1}$ in P. palmivora P376.

Our results also show that phosphonate inhibition resulted in a significant increase in the level of phosphate accumulated per unit mass. The observation has been confirmed in independent studies using different growth conditions and different analytical methods (J. O. Niere \& B. R. Grant, unpublished). Increases in $\mathrm{Pi}_{i}$ concentration in phosphonate-inhibited mycelia were accompanied by massive increases in pyrophosphate and polyphosphate. Phosphonate does not accelerate the rate of phosphate uptake (Griffith et al., 1989 b) and the relative increase in the $\mathrm{Pi}_{\mathrm{i}}$ concentration resulted from growth depression rather than increased phosphate uptake (J. O. Niere \& B. R. Grant, unpublished). However, in the presence of phosphonate, the phosphate which enters the organism is not converted to organic phosphate to the same extent as it is in the absence of the anion but accumulates as pyro- and polyphosphate.

We conclude that differences in sensitivity to phosphonate are due in part to differences in the capacity of the organism to exclude the anion in the presence of physiological concentrations of phosphate. This may be a general phenomenon, but within the genus Phytophthora there are further differences in sensitivity at one or more internal sites.

This work was supported in part by ARC grant A09130971 to B. R.G. J.M.G. was the holder of a University of Melbourne Women`s
Fellowship. The technical assistance of Jill Harris and Sieu Cleland is acknowledged together with the contribution of Amanda Davis in making available her unpublished data on Fusarium.

\section{References}

Barchietto, T., Saindrenan, P. \& Bompeix, G. (1988). Uptake and utilisation of phosphite by Phytophthora citrophthora and Nectria haemutococca in relation to its selective toxicity. Pesticide Science $\mathbf{2 2}$, $54-58$.

Barchietto, T., Samndenay, P. \& Bompeix, G. (1989). Characterisation of phosphonate uptake in two Phytophthora spp. and its inhibition by phosphate. Archites of Microbiology 15I, 54-58.

Barchietto, T., Saindrenan, P. \& Bompeix, G. (1992). Physiological responses of Phytophthora citrophthora to a sub-inhibitory concentration of phosphonate. Pesticide Chemistry and Physiology 42, $151-166$.

Bompeix, G. \& SaIndrenan, P. (1984). In vitro antifungal activity of Fosetyl Al and phosphorous acid on Phytophthora species. Fruits 39, $777-786$.

CATEN, C. E. \& Jinks, J. L. (1968). Spontaneous variation in single isolates of Phytophthora infestans. 1. Cultural variation. Canadian Journal of Botany 46, 329-348.

Coffey, M. D. \& Ounmette, D. G. (1989). Phosphonates: Antifungal compounds against Oomycetes. In Nitrogen, Phosphorus and Sulphur Utilisation by Fungi, British Mycological Society Symposium, pp. 107-129. Edited by L. Boddy, R. Marchant and D. J. Read. Cambridge: Cambridge University Press.

COHEN, Y. \& COFFEY, M. D. (1986). Systemic fungicides and the control of oomycetes. Annual Review of Phytopathology 24, 311-338.

Davts, A. J., SAY, M., SnOw, A. J. \& GRant, B. R. (1993). Sensitivity of Fusarium oxysporum $f$ sp. cubense to phosphonate. Plant Pathology (in the press).

Dolas, T. E. \& CofFey, M. D. (1988). Correlative in vitro and in vino behaviour of mutant strains of Phytophthora palmivora expressing different resistances to phosphorous acid and fosetyl-Na. Phytopathology 78, 974-978.

DiNstan, R. H., SMilite. R. H. \& GRANt, B. R. (1990). The effects of subtoxic levels of phosphonate on the metabolism and potential virulence factors of Phytophthora palmivora. Physiological and Molecular Plant Pathology 36, 205-220.

FENv, M. E. \& COFFEY, M. D. (1984). Studies on the in vitro and in vino antifungal activity of fosetyl-Al and phosphorous acid. Phytopathology 74, 606-611

Grant, B. R, Griffith, J. M., Irving, H. R. \& Radda, M. (1984). An improved method for the synchronous production of zoospores from Phviophthora palmivora. Experimental Mycology 8, 382-385.

Griffith, J. M., Akins, L. A. \& Grant, B. R. (1989a). Properties of the phosphate and phosphite transport systems of Phytophthora palmivora. Archives of Microbiology 152, 430-436.

Griffith, I. M., Smillif, R. H., Niere, J. O. \& Grant, B. R. (1989b). Effect of phosphate on the toxicity of phosphite in Phytophthora palmitora. Archives of Microbiology' 152, 425429

Griffith, J. M.. Smillie, R. H. \& Grant, B. R. (1990). Alterations in nucleotide and pyrophosphate levels in Phytophthora palmivora following exposure to the antifungal agent potassium phosphonate (phosphite). Journal of General Microbiology 136, 1285-1291.

Griffith, J. M., Davis, A. J. \& Grant, B. R. (1992). Target sites of fungicides to control Oomycetes. In Target Sites of Fungicide Action, pp. 69-100. Edited by W. Koller. Boca Raton Florida: CRC Press.

Guest, D. \& GRant, B. (1991). The complex action of phosphonates as antifungal agents. Biological Reviews 66, 159187.

Heaton, J. B. \& Dullahide, S. R. (1990). Efficacy of phosphonic acid in other host pathogenic systems. Australasian Plant Pathology 19, 133-134.

HENDRIX, J. W. (1965). Influence of sterols on growth and reproduction of Pythium and Phytophthora spp. Phytopathology 55, 790-797.

HeNDRIX, J. W. \& A PPLE, J. L. (1964). Fats and fatty acid derivatives as growth stimulants and carbon sources for Phytophthora parasitica var nicotianae. Phytopathology 54, 987994.

Irving, H. R., Grifftth, J. M. \& Grant, B. R. (1984). Calcium efflux 
associated with encystment of Phytophthora palmivora zoospores. Cell Calcium 5, 487-500.

Niere, J. O., Griffith, J. M. \& GRANT, B. R. (1990). ${ }^{31}$ P NMR studies on the effect of phosphite on Phytophthora palmivora. Journal of General Microbiology 136, 147-156.

Rawn, C. D. \& VAN ETTEN, J. L. (1974). A shake culture method for Pythiaceae applicable to rapid small scale assay of vegetative physiology. Phytopathology 68, 1384-1388.

Ribeiro, O. K., ERwin, D. C. \& Zentmyer, G. A. (1975). An improved synthetic medium for oospore production and germination of several Phytophthora species. Mycologia 67, 1012-1019.

ROSENBerg, H. \& La Nauze, J. M. (1968). Isolation of a mutant of
Bacillus cereus deficient in phosphate transport. Biochimica et Biophysica Acta 156, 381-388.

Smillie, R. H., Grant, B. R. \& Guest, D. I. (1989). The mode of action of phosphite: evidence for both the direct and indirect modes of action on three species of plants. Phytopathology 79, 921-926.

Tokunaga, J. \& BarTnICKi-GarCia, S. (1971). Cyst wall formation and endogenous carbohydrate utilisation during synchronous encystment of Phytophthora palmivora zoospores. Archiv für Microbiologie 79, 283-292.

ZweCK, S., Hütterman, A. \& Chet, I. (1978). A convenient method of preparing inocula of homogenised mycelia. Experimental Mycology 2, 377-378. 